\title{
OS BRINDES E A ATRAÇÃO DE ÍNDIOS NO POSTO FRATERNIDADE NA RAIA DA FRONTEIRA OESTE PELO SPI*
}

\author{
Lucybeth Camargo de Arruda**
}

RESUMO: Criado para atuar junto aos índios do Brasil, o SPI - Serviço de Proteção aos Índios - foi fundamental para mediar os conflitos existentes entre grupos indigenas e não-índios e, assim, permitir o povoamento colonizatório, no início do século $\mathrm{XX}$, a partir de 1910. Nesse contexto histórico-social, o objetivo é esboçar uma antropologia histórica através da micro-análise da documentação do SPI lançando luz nas relações produzidas do contato por meio dos brindes e a reação dos indios, nesse caso, o povo Umutina, no Estado de Mato Grosso - Fronteira Oeste, no periodo de 1910 a 1923.

PALAVRAS-CHAVE: Política Indigenista, SPI, Pacificação e Resistência.

Aos 12 dias do mês de outubro de 1913, de conformidade com instruções do Cidadão Coronel Cândido Mariano da Silva Rondon, chefe da Comissão de Linhas Telegráficas Estratégicas de Mato Grosso ao Amazonas e Diretor do Serviço de Proteção aos Índios c Localização de Trabalhadores Nacionais (...) foi transferido para este Serviço,

* Este texto ć um trecho de minha dissertação de Mestrado cm História e resolvi retomá-lo para pensar de forma mais detida o diálogo entre Antropologia c História.

** Doutoranda do Programa de P’́s-Graduação cm Antropologia Social, PPGAS-IFCII/ UNICAMP. Bolsista da l'undação de Amparo à l'esquisa de Mato Grosso - Fapemat. 


\begin{abstract}
o Posto de Atração "Fraternidade Indigena" (...) destinando-se à pacificação dos Índios Barbados' (...) scndo encarregado do mesmo posto o cidadão Severiano Godofredo de Albuquerque. ${ }^{2}$
\end{abstract}

Esta ata de transferência é um dos exemplos do investimento que o Estado Brasileiro, através do Serviço de Proteção aos Índios e Localização de Trabalhadores Nacionais -SPILTN ${ }^{3}$, passa a adotar junto aos índios do Brasil a partir de 1910, quando o órgão é criado. O SPI ${ }^{4}$ passa a trabalhar em parceria com a Comissão de Linhas Telegráficas Estratégicas de Mato Grosso ao Amazonas, conhecida também por Linhas Telegráficas de Rondon, Missão Rondon ou ainda, Comissão Rondon, pelo menos quando o assunto é índio. A Missão Rondon dispunha de um objetivo nacional, formulado pelo governo de Affonso Penna, de incorporação efetiva dos territórios do Acre, do Purus e Juruá ao Brasil (Maciel, 1997):

\footnotetext{
'O ctnônimo desse grupo indigena ć Umutina, também conhecidos por Barbados. $A$ barba ou o uso do cavanhaque dos Umutina justificou o apclido de "Barbados", dado pelos "civilizados". Scgundo os estudos etnográficos feitos por Harald Schultz, a grafia correta do nome desta ctnia, a partir de sua autodenominação, scria Um "t $y n a$, cuja pronúncia tra\% o primciro "u" nasalizado e o " $y$ " da terceira sílaba post-palatizado. lodavia, com a intenção de simplificar a pronúncia c a grafia, Schultz decidiu chamá-los de Umutina. Kalervo Oberg c Max Schmidt, que também estudaram os Umutina escrevem cm suas publicações Umotina. Fico aqui com a grafia proposta por Schultz.SCHUL'1Z, Harald. Informaföes efnográficas sobre os Umutina. Separata da Revista do Muscu Paulista. Nova Séric - Volume XIII. 1962.

2 Ata da transferência para a Inspetoria do Serviço de Proteção aos Índios c Localização de Trabalhadores Nacionais em Mato Grosso, do Posto de Atração dos Índios Barbados Fraternidade Indigena - situado próximo à Povoação da "Barra", à margem do rio dos Bugres. Em 12 de outubro de 1913. Microfilme 200. Fotograma 000589. Muscu do Índio/FUNAI-RJ. ${ }^{3}$ Conforme Lima (1995, p. 39) o Serviço de l'roteção aos Índios e I ocalização de 'Irabalhadores Nacionais (SPILTN) - estrutura organizacional estatizada desde 1910, considerando-o como lugar do qual se luta para centralizar e manter o monopólio sobre o exercício de diversos poderes sobre os povos nativos. Sua finalidade seria implantar, gerir e reproduzir tal forma de poder de Estado, com suas técnicas (príticas administrativas), principais normas e leis, constituidas e constituintes de um modo de governo sobre o que seria denominado de indio (ou seu plural, indios), status que se engendra e transforma ao engendrá-lo.

${ }^{4}$ Forma abreviada de SPILIN. $\Lambda$ partir de 1918, segue apenas como SPI. (Lima, 1995, p. 11).
} 
A nova comissão se encarregaria não só da construção propriamente dita de linhas telegraphicas, como também de todos os serviços que se prendessem ao completo conhecimento da região que se ia atravessar sob o ponto de vista geográphico, botânico e mineralógico e mais ainda do descobrimento das populações indigenas que la existissem as quais ficaram sob os cuidados da comissão no intuito de se cvitar que a penetração de seus territórios fosse acompanhada das calamidades e cruezas sofridas pelos habitantes de outras regiões onde se haviam cstabelecido estradas de ferro ou de rodagem, instalado linhas de navegação ou feito simples incursões de explorações geográphicas ou ainda de demarcação de limites 5 .

Inserido nesse projeto maior da Comissão Rondon, que iniciou a incursão em 1907, estava o projeto de localização e pacificação dos índios Umutina. Para Octaviano Cabral (1963), a investida de Rondon junto aos Umutina já se dava com a intenção de instalar um posto indígena modelo ${ }^{6}$, projeto esse que, de acordo com Cabral, começou a tornar-se realidade com a abertura do Posto Fraternidade. $A$ idéia de Rondon era fundar

ali a aldeia com a denominação de Posto Fraternidade Indígena, os indios nas suas casinholas de telha $\mathrm{c}$ até luz clétrica, as vacas leiteiras pastando no campestre aramado, limitado pelas águas dos rios Paraguai e Bugres (1963, p. 281).

Essa construção de Rondon, que era a concepção da própria Comissão, cvidenciava o seu idealismo frente aos grupos indígenas do Brasil e mais, segundo Lylia Galletti (2000), a sua ação junto à Comissão representava a inserção efetiva do progresso via ação civilizatória dos índios:

${ }^{5}$ Missão Rondon III. Jornal do Comércio, de 12 de junho de 1913. Fillme 382. Fotograma 059. Muscu do Índio/FUNAI-RJ.

'A referência ao posto modelo é, no sentido do Posto Fraternidade, alcançar todos os objetivos do processo de civilização proposto por Rondon c conseqüentemente pelo SPI. 
Ao mesmo tempo, a Comissão descortinava os sertões mato-grossenses como uma fronteira do país, na sua dupla acepção de espaço da barbárie e terras novas - região abundante em recursos naturais, que ela própria cncarregava-se de inventariar - a ser colonizada pela nação (2000, p. 234).

Retomando o documento da ata de transferência das responsabilidades do Posto de Atração Fraternidade Indígena da Comissão das Linhas Telegráficas para o SPILTN, quero cvidenciar que esse ato marcou também a fundação do Posto $^{7}$ de Atração com o nome Fraternidade Indígena, enunciado carregado de sentidos, podendo significar, por um lado, a ação fraternal efetivamente pretendida, que estaria por ser desempenhada pelos membros do SPI junto aos índios, engajados na função de arrancá-los desse estado absolutamente primitivo, uma vez que eram considerados, de acordo com uma visão positivista, pessoas incapazes de gerir a sua própria sobrevivência, seja pela inferioridade que lhe era outorgada, seja por outro motivo qualquer, talvez mais estratégico, como uma suposta "ação fraternal" para conseguir a pacificação a qualquer preço, passos indispensáveis ao domínio do território e das próprias ações dos índios.

O nome do posto "Fraternidade Indígena", assim batizado pelo Coronel Cândido Mariano Rondon, poderia sugerir, em princípio, uma influência da Igreja Cristã Católica e/ou de outra ordem religiosa; afinal, a palavra "fraternidade" é de uso comum no cristianismo. Fortaleceria essa hipótese o fato das ações indigenistas do Estado brasileiro, nos séculos XVIII e XIX, terem se dado principalmente através dos missionários, que por muitas vezes desempenharam (e em alguns contextos ainda desempenham) funções nas áreas de educação e saúde junto aos povos indígenas do Brasil.

Todavia, ainda que a presença dos missionários possa indicar uma influência na escolha do nome, consideramos que o termo "fraternidade", no

\footnotetext{
${ }^{7}$ Posto significa um cspaço definido para o trabalho de concentração, agremiação de indios considerados arredios c hostis no relacionamento com os não-indios. Inclui populaçōes e terras numa rede nacional de vigilancia e controle, a partir de unn centro uinico de poder. Unidades de afáa locais do aparellso de governo dos indios. (LIMA, 1995, p.75)
}

Temáticas, Campinas, 16(31/32):219-241, jan./jun. 2008 
caso do posto, está ligado às concepções científicas da época que seguiam o Apostolado Leigo de Auguste Comte. "Fraterno", no universo positivista, remete ao reforço da nacionalidade, da Pátria que acolhe e ampara a todos $\mathrm{e}$ traz consigo outros enunciados como moral, amizade, ser pacífico, etc. $A$ ata de fundação do SPI apresenta, literalmente, esse discurso:

O presidente Nilo Peçanha convencido de que a "República" é o governo da fraternidade entre os homens e que o principal dever de qualquer governo é a proteção à vida e à propriedade dos seus jurisdicionados resolveu, em 1910, por intermédio de seu ministro Rodolfo de Miranda, fundar o Serviço de Proteção aos Índios para por cabo às atrocidades que os aborígines vinham sofrendo desde a descoberta do Brasil, em foco na ocasião pelas lutas e recíprocos massacres ${ }^{8}$.

O termo veicula o discurso e a política que sustentavam as ações do SPI, cujos objetivos de integração exigiam, de fato e a qualquer custo, a substituição dos métodos repressores e violentos, que visavam à exclusão, por ações pacíficas e pacificadoras, com o objetivo de firmar os povos indígenas no estágio de civilidade.

Essa confiança plena na possibilidade dos índios alcançarem o estágio de civilidade e que depois de "civilizados" cles viveriam nas suas casinholas de telha e até luz elétrica (Cabral, 1963, p. 281), não estava presente somente nos discursos de Rondon e dos membros de cargos de direção do SPI. Os encarregados de posto, nos scus relatórios e pedidos aos seus superiores, tomavam a todo o momento a "evolução" do indígena como certa, julgando ser apenas uma questão de tempo o alcance deste fim por vias fraternais $c$ pacíficas:

${ }^{8}$ Exposição sobre o Serviço de Proteção aos Índios. Documento de 1933 que traz a ata de fundação do SPI. Microfilme 380. Fotograma 884. Muscu do İndio/FUNAI-RJ. Grifos meus. 
(...) $\mathrm{cm}$ bencfício do desenvolvimento do Posto de Atração "Fraternidade Indígena" que há três anos venho desempenhando com o mais vivo esforço ao meu alcance nestes páramos do alto Paraguai. (...) Estes heróicos filhos das selvas que, um dia, não mui longe, incorporados à comunhão brasileira, trarão grande cópia de (sic) bencfícios à Pátria, (...) Afim de que unidos consigamos o fim bendito de tê-los como trabalhadores nacionais, sem que para isso tenhamos de coagi-los e obrigá-los aos serviços rudes do machado, da foice $\mathrm{c}$ da enchada. É preciso que levam e que a República colha o (sic) o dispêndio já gasto c por gastar ainda, até conseguir aquele fim. ${ }^{\text {? }}$

O evolucionismo social, de acordo com Lilia Moritz Schwarcz (1993), tomava sempre uma perspectiva comparativa numa relação de desigualdade que obedecia a uma escala hierárquica:

Civilização c progresso, termos privilegiados da época, cram entendidos não enquanto conceitos específicos de uma determinada sociedade, mas como modelos universais. Segundo os evolucionistas sociais, em todas as partes do mundo a cultura teria se desenvolvido em estados sucessivos, caracterizados por organizações econômicas e sociais específicas. Esses estágios, entendidos como únicos e obrigatórios - já que toda a humanidade deveria passar por eles -, seguiam determinada direção, que ia sempre do mais simples ao mais complexo e diferenciado. Tratava-se de entender toda e qualquer diferença como contingente, como se o conjunto da humanidade estivesse sujeito a passar pelos mesmos estágios de progresso cvolutivo (Schwarcz, 1993, p. 57 e 58).

'Informação ao Inspetor do SPIL'IN, no cstado de Mato Grosso Adriano Metello. Microfilme 200. Fotogramas : 000635 c 636. Muscu do Índio/FUNAI-RJ. Grifo meu.

Temáticas, Campinas, 16(31/32):219-241, jan./jun. 2008 
Para compreender as ações que deram existência ao Posto Fraternidade Indígena, o que anunciavam e o que significavam, é necessário articular o que aconteceu em Mato Grosso, circunscrito localmente ao território do posto, à política geral do órgão, cuja responsabilidade era gerir as questões indígenas ${ }^{10}$. Entretanto, essa política incluía várias práticas e entre clas a distribuição de brindes será apresentada neste trabalho de maneira mais detida, de modo a compor o nosso objeto - que perpassa a situação do contato por meio dos "presentes" - e através dessa prática observar as ações dos índios frente a cssa estratégia de aproximação.

Além do suporte tcórico da macro-política, abordada por Antônio Carlos de Souza Lima, o autor Michel de Certeau (1994) também ajudou a pensar essa questão, visto que encontrei $\mathrm{cm}$ sua obra $A$ Invenção do CotidianoModos de Fazer, um conceito de tática que me deu subsídios para pensar a reação dos índios na "contramão" das ações articuladas pelo Estado. Considerando o foco de atenção deste trabalho, voltado para o cotidiano do Posto Fraternidade Indigena, a micro-história, segundo Jacques Revel (2000), pareceu-nos o caminho possível, entendendo que a situação da micro-análise "deve permitir o enriquecimento da análise social, torná-la mais complexa, pois leva em conta aspectos diferentes, inesperados, multiplicados da experiência coletiva" (2000, p. 18). O autor afirma ainda, que:

A redução de escala, o interesse por destinos específicos, por escolhas confrontadas a limitações, convidam a não se deixar subjugar pela tirania do fato consumado - 'aquilo que efetivamente aconteceu' - e a analisar as condutas, individuais e coletivas, em termos de possibilidades, que o historiador pode tentar descrever e compreender (Revel, 1998, págs. 19-20).

${ }^{10}$ A política indigenista aqui envolvida não $\mathrm{c} \mathrm{cm}$ si o foco deste cnsaio. lara uma abordagem sobre o assunto, ver: Lima (1987; 1989; 1992 c 1995). Parte considerável das instruções ou do discurso civilizatório que aparece no trabalho de $\Lambda$ ntônio Carlos de Souza Lima, em um macro contexto do governo brasileiro, foi também identificada na documentação do Posto Fraternidade Indigena.

Temáticas, Campinas, 16(31/32):219-241, jan./jun. 2008 
Concordando que a micro-história apresenta-se como o melhor caminho para a construção deste texto, consideramos imprescindível uma articulação com a macro-história; oscilando nesse exercício de ora fechar a lente da objetiva, ora abrir, para que possamos avançar numa leitura onde seja possivel apreender os vários contextos inseridos nas tramas do Posto Fraternidade Indígena. O exercício de redução da escala entre uma perspectiva e outra nos possibilita compreender uma história social específica num espaço recortado, colocando em evidência agentes históricos e suas singularidades, em contraposição a uma abordagem onde estes encontram-se maciçamente ausentes ou são "vistos" de uma maneira ainda homogeneizante e passiva. A idéia desse tipo de abordagem é permitir a visualização das multiplicidades nas ações. Este ensaio pretende engrossar as fileiras dos trabalhos que consideram que a história dos índios vai além do reconhecimento do papel dominador do Estado e das elites, por um lado, e dos índios como meras vítimas do processo, por outro (Monteiro, 1995).

Se através da pesquisa bibliográfica podemos identificar a política de aldeamento, a documentação específica do posto-que registra as pequenas ações de modo detalhado - torna possível caracterizar a produção do cotidiano do posto e das relações deste com o seu entorno (fazendas, garimpeiros e cidade), permitindo identificar a participação de cada agente social, seja ele o "civilizado" e suas categorias (funcionário do SPI, fazendeiro, etnólogo, etc.), seja ele o índio (Umutina).

As questões deste trabalho foram construídas a partir da leitura dos documentos do SPILTN, arquivados no Museu do Índio, no Rio de Janeiro. Nessa documentação foi possível encontrar atas e correspondências de agentes encarregados do Posto Fraternidade, endereçadas à Inspetoria Regional 06 do SPI, localizada em Cuiabá no Estado do Mato Grosso, ou à Inspetoria Nacional, ligada ao Ministério da Agricultura Indústria c Comércio" ${ }^{11}$ Há

\footnotetext{
${ }^{11}$ Os documentos do Posto Fraternidade Indigena eram enviados para a Inspetoria $06 \mathrm{c}$ alguns diretamente para a Inspetoria Nacional - SPI, órgão que cstava ligado ao Ministério da Agricultura até $1930 \mathrm{c}$ depois foi transferido para o Ministério do 'Trabalho, Indústria c Comércio, c em 1934 para o Ministério da Guerra, pois Rondon e os responsaveis por gerir a política indigenista $\mathrm{em}$ nível nacional, entendiam que a questão da integração dos povos indigenas à
}

Temáticas, Campinas, 16(31/32):219-241, jan./jun. 2008 
documentos que são instruções para o Posto Fraternidade, oriundas do Serviço de Proteção, além de documentos (ofícios, telegramas c cartas) enviados e recebidos do próprio Ministério.

Entre 1913 e 1921, o posto ficou sob o comando do funcionário Severiano Albuquerque. Os administradores, denominados de encarregados, prestavam conta de tudo que cra feito nos limites do território do posto. Havia uma periodicidade de produção de relatórios informando ao SPI aspectos do cotidiano, como a colheita, as benfeitorias, roçadas, derrubadas e plantações, criação, pastagem, chegada e saída de índios, as visitas de índios ao posto, sobre dados anuais de nascimento e morte deste povo, além de pequenos acontecimentos.

Dentro do recorte temporal proposto no presente texto ${ }^{12}$, identificamos relatórios com periodicidade mensal, outros semestrais $\mathrm{c}$ alguns anuais. Além de relatórios, encontramos também muitos telegramas, cartas e bilhetes, que eram enviados de acordo com a necessidade de comunicação. A documentação traz detalhes também sobre o que era consumido ou gasto na manutenção do posto, sobre as listas dos brindes utilizados na atração e pacificação, e ainda informavam sobre o estado sanitário do posto.

O caso dos Umutina chama a atenção pelo tempo - $32 \operatorname{anos}^{13}$ - do processo de pacificação, uma vez que é notória a ação reativa desses índios às disciplinas impostas pelo posto e, por outro lado, a insistência do SPI cm assujeitá-los, uma vez que, já em 1913, o documento registra a sua "pacificação":

Mais duas tribos foram pacificadas $\mathrm{em}$ Mato Grosso durante o ano de 1913: a dos Cabixis c a dos Barbados, a

nação brasileira era uma questão de segurança nacional, pois antes de serem pacificados c civilizados, cram considerados selvagens e de natureza perigosa para o Brasil. P'ara saber mais ver $\operatorname{lima}$ (1995).

12 O recorte temporal trabalhado neste ensaio é de 1910 (quando o SPI é criado) a 1923, com efetiva com moradores Umutina. No caso, as crianças órfas de uma epidemia que dizimou parte considerável do grupo após o contato com os funcionários do Serviço cm suas aldeias.

${ }^{13}$ Este tempo foi calculado por mim, levando em consideração o período da fundação do posto c a vinda de todos os membros do grupo Umutina que sobreviveram ao processo de redução desse povo no espaço do posto. Isto é, de 1913 a 1945.

Temáticas, Campinas, 16(31/32):219-241, jan./jun. 2008 
primeira por funcionários da respectiva inspetoria e a segunda por pessoal das linhas telegráficas sob a direção do Coronel Rondon. Os Cabixy habitam as vizinhanças do Sararé e os Barbados o Alto Paraguay. Uns c outros viviam $\mathrm{cm}$ contínua guerra com os civilizados, principalmente os últimos com os seringueiros da mata da Poaia ${ }^{14}$.

$A$ atração dos índios por meio dos brindes se deu num processo de política de aldeamento que queremos aqui identificar/analisar através dos registros do Posto Fraternidade Indígena. O esforço civilizatório do "indigenismo" federal junto aos índios do Brasil compreendeu, no caso dos Umutina, um intrincado jogo de movimentos - próximos ao xadrez, configurando movimentos de ações e reações. As táticas, na trilha de Michel de Certeau $^{15}$ (1994), correspondem às movimentações reativas às ações de assujeitamentos. A tática não se propõe a nada a longo prazo; o presente ou, no máximo, o futuro imediato são o seu tempo:

A tática depende do tempo, vigiando para "captar no vôo" possibilidades de ganho. O que ela ganha, não o guarda. Tem que constantemente que jogar com os acontecimentos para os transformar em "ocasiões". Sem cessar, o fraco deve tirar partido de forças que lhe são estranhas. Ele o consegue em momentos oportunos onde combina elementos heterogêneos (...), mas a sua síntese intelectual tem por forma não um discurso, mas a própria decisão, ato e maneira de aproveitar a "ocasião". (Certeau, 1994, p. 47)

Ao longo do processo de instalação do posto Fraternidade Indígena fica evidente que a "doação" de brindes não foi uma prática realizada apenas

\footnotetext{
${ }^{14}$ Relatório da Inspetoria Regional em Mato Grosso endereçado ao SPIL'I'N, no Ministério da Agricultura, 1913. Microfilme 200. Fotograma 1224. Museu do Índio/IFUNAI-RJ.

${ }^{15} \mathrm{O}$ empréstimo deste conceito faço pela primeira vez em minha dissertação de Mestrado "Posto Fraternidade Indigena: Estratégias de Civilização c Táticas de Resistência 1913-1945".
}

Temáticas, Campinas, 16(31/32):219-241, jan./jun. 2008 
nos primeiros anos de vida dessa unidade, e que o seu sentido é mais amplo que aquele que se supõe numa primeira análise. $A$ instrução do SPI apontava para a utilização dessa prática no início do processo, como forma de estabelecer contato e de incentivar os índios a viver no posto, cuja infra-estrutura ia ganhando formato de centro agrícola, povoação, e por fim, de uma comunidade, a partir da fixação de moradias e do estabelecimento de ciclos de trabalhos rurais que os próprios índios começaram a desenvolver ao se estabelecerem no posto.

$\mathrm{Na}$ análise dos relatórios, telegramas e cartas que fazem referência ao sistema de brindes, percebemos algo mais complexo que o simples ato de doar/seduzir que se encontra nesta relação. Assim, deslocamos o foco, antes centrado na perspectiva do SPI, para a reação dos índios frente a esta atuação que estava interligada a várias outras. Estamos falando da movimentação dos Umutina a partir do protocolo que foi estabelecido pelo sistema de brindes. Um nível de complexidade se encontra na análise da utilização dos brindes, que têm sentidos diferentes tanto para os Umutina quanto para os agentes do SPI.

Na perspectiva dos agentes, que buscavam alcançar os objetivos da "integração civilizatória", o aceite dos brindes pelos índios significava uma abertura para possiveis diálogos. Todavia, no entendimento dos índios, a análise dos documentos nos sugere que não havia "interesses de longo prazo", ou seja, a relação mediada pelos brindes era instantânea. Cada situação de oferecimento de brindes deveria ser "resolvida" no âmbito daquela circunstância, por isso estabeleciam o contato, ou seja, "aceitavam os brindes" e depois retornavam para a mata, sem nenhuma perspectiva futura para a fixação de outras relações.

No campo das relações dos Umutina, o trato e o sistema de trocas existentes possibilitavam a utilização dos brindes em nome de uma relação amistosa. Assim, depois de várias incursões desta natureza, os brindes passavam a ser trocados por visitas mais demoradas aos agentes - que faziam de tudo para seduzi-los e estabelecer um vínculo mais próximo e de intimidade sempre com a intenção de uma permanência mais duradoura, quiçá definitiva.

Passados alguns anos, a troca brindes/amistosidade foi substituída por brindes/trabalho na lavoura. Ainda aqui, o que poderia ser entendido como 
uma proximidade maior com o "sentido dos agentes" (civilizatório) pode ser colocado em dúvida, considerando que cada situação de utilização dos brindes era resolvida separadamente, ou seja, os brindes eram trocados por um período específico de trabalho e ponto final. Provavelmente porque supunham que a significação atribuída ao sistema de brindes pelos índios encerrava-se naquele momento; os membros do SPI, mesmo depois de vários contatos amistosos, não entendiam porque os Umutina seguiam desconfiados do projeto civilizatório e mais, se viram na situação inversa, ou seja, ao invés de cooptá-los (os índios) para morar no posto de atração, se sentiram cooptados a ponto de precisarem estabelecer novas negociações, de modo a não colocar em risco os supostos "avanços" (em relação ao processo civilizatório) conseguidos pela doação dos brindes até aquele momento.

Não estando os indios completamente pacificados, isto é, sem noção alguma da proteção que lhe damos e da garantia que o serviço lhes proporciona amparando-os, defendendoos das depredações que há quarenta e tantos anos vinham sofrendo com as incursões pelos seus pinotes (sic), ainda continuam eles a apresentarem no posto completamente armados e desconfiados. Pelo processo adaptado de chamálos a civilização por meio de brindes e agrados, estamos na situação de suportar todas as suas exigências, não nos sendo lícito lançar mão da menor violência sob pena de não mais continuarem nas suas visitas no posto ${ }^{16}$.

Percebe-se que o processo de cooptação e atração dos índios precisava de mudanças nas relações até então estabclecidas. O que parecia ser tão simples e óbvio no esquema montado pelo SPI estava se mostrando complexo, necessitando de negociação de ambas as partes. Afinal, o anúncio da pacificação foi feito em 1913 c este documento é de 1918.

\footnotetext{
${ }^{16}$ Correspondència enviada para a Inspetoria Regional de Mato Grosso do encarregado do Posto Fraternidade, em $1^{\circ}$ de maio de 1918. Microfilme 200. Fotogramas 703,704 e 705.
Muscu do Índio/FUNAI - RJ. Grifo meu.
} 
O que ficava tácito era que o "coagido" em questão também possuía alguma margem de manobra ou a possibilidade de agir taticamente, o que em geral, pelo menos naquele contexto, era ignorado de tal modo, a ponto de imprimir na relação estabelecida a necessidade (da parte dos agentes) de uma reinvenção das relações, de uma nova negociação ou de novos movimentos. As táticas Umutina configuraram, nesse sentido, uma ação reativa.

Assim, a ação dos agentes "produzia" a tática dos Umutina e esta tática produzia também a relação de força. Afirmar que os Umutina, como um todo, aceitaram a cooptação, sc deixaram ludibriar pelos agentes, deixaram de ser índios, enfim, todas e quaisquer afirmações desse caráter são conclusões simplistas que subestimam a capacidade de agir dos índios (reação que não se limitou, provavelmente, aos Umutina), bem como ignoram o intricado jogo de relações, de movimentos de negociação, avanços e recuos, que constituíam o processo de instalação de um posto de atração.

No decorrer dos primeiros anos muitas foram as tentativas de trazêlos para o posto por meio dos brindes. Se, inicialmente, essas práticas resultaram no estabelecimento de uma relação amistosa, vimos também que a doação é logo transformada em sistema de trocas. Na perspectiva da troca a suspensão dos brindes podia significar a interrupção das relações. Um telegrama enviado em 13 de setembro de 1915 nos revela a angústia do agente ao solicitar mais brindes para a Inspetoria Regional de Mato Grosso, em Cuiabá. O documento clamava: Precisamos brindes mandar índios urgente. Saúde, Severiano Godofredo Albuquerque ${ }^{17}$.

$\mathrm{Na}$ falta dos brindes, além da interrupção dos contatos, a relação corria o risco de perder a "amistosidade". Em relatório de dezembro de 1915, enviado ao Inspetor Regional em Mato Grosso, Adriano Metello, o encarregado do posto expõe a sua compreensão do que se passava em relação aos brindes e aos indigenas, assinalando sua argúcia em "deixar" os índios pensarem que tinham o controle da situação:

17 Telegrama para Cuiabá de Barra dos Bugres, em 13 de setembro de 1915, solicitando brindes para os Umutina. Microfilme 200. Museu do Índio/FUNAI - RJ.

Temáticas, Campinas, 16(31/32):219-241, jan./jun. 2008 
Com a pacificação que efetuei a 16 de agosto de 1913, os indios muitos se acostumaram com o processo de agrado pela permuta da dádiva; subjugaram-nos pelo poderio de suas armas, conforme pensaram e pensam até hoje a pormos-lhes tudo quanto temos ameaçando-nos entendendo eles que diante das suas ameaças é que lhes suprimos de brindes ${ }^{18}$.

No mesmo documento, mais adiante, o encarregado Severiano Albuquerque seguiu analisando diferentes situações de contato junto aos Umutina e concluiu que estes índios já viviam em contato com os civilizados desde muito antes, tidos como "semi-civilizados" e, exatamente por essas características, estes eram de difícil pacificação definitiva por causa dos vícios que possuíam ou que foram se constituindo com os contatos anteriores. No caso dos Umutina, Albuquerque acreditava que somente a imposição da força poderia corrigi-los:

A pacificação da tribo que jamais teve contato com civilizado é mais fácil c obedece ela melhor ao princípio da civilização do que os que vivem em promiscuidade ou lutas com civilizados! Com os índios Barbados, dá-se ao contrário do que pensávamos. É para corrigi-los do mal que geralmente os índios semi-civilizados tem do roubo, é preciso sem exagero de errar, aumentar o número de homens no Posto para impô-los pela moral e pelo bem desse modo a que trazem consigo e reuni-los em povoado ${ }^{19}$.

Em outras palavras, a confiança na atitude da demonstração de força, através do aumento da quantidade de homens no posto, indica que o sistema

\footnotetext{
${ }^{18}$ Relatório no formato de carta ao Inspetor Regional de Mato Grosso Adriano Metelo sobre o andamento dos trabalhos no posto Fraternidade Indigena. Microfilme 200. Fotograma 637. Museu do Índio/FUNAI - RJ.

${ }^{19}$ Relatório no formato de carta ao Inspetor Regional de Mato Grosso Adriano Metelo sobre o andamento dos trabalhos no posto Fraternidade Indígena. Microfilme 200. Fotograma 637. Museu do Índio/FUNAI - RJ.
} 
dos brindes não estava surtindo tanto efeito como se afirmava. Ao contrário, esse sistema acabou produzindo resultados inesperados e vícios como o roubo, nas palavras do encarregado:

Durante estes três anos de serviço tenho empregado toda a minha energia e devotamento plantando as armas que constituem a nossa lavoura, tudo, porém, sem resultado para o Posto. A nossa primeira plantação é o milho e com esse seguem-se o arroz e o feijão, a mandioca $\mathrm{c}$ a banana: as três primeiras, mal chegam ao período da gramação, são colhidos c levados pelos índios em turma de 20 a 30 que se sucedem diurnamente com carregamentos avultadíssimos. ${ }^{20}$

O que parecia estar sob o controle de Severiano, mesmo quando ele fingia reconhecer que o domínio da situação era dos Umutina, quando aceitava suas imposições como mais uma forma de aproximação, vai, aos poucos, se apresentando na verdade como outra coisa. O relatório abaixo continua com a exposição dos fatos de Severiano que, não admitindo a possibilidade de estar de certa forma, e de fato, nas mãos dos índios, segue buscando explicações:

(..) Mais uma vez repito, limitando-me unicamente no scguinte: Os indios Barbados são brutos por excelência, entendem que o agrado que lhes fazemos não é mais do que covardia nossa e de tudo pensam cles nos dominarem pelas suas armas!?

A crença absoluta nos estágios evolutivos e na condição inferior dos índios por vezes tornava-se improvável, senão impossível. Precisamos considerar, por exemplo, que talvez os Umutina estivessem testando a

\footnotetext{
${ }^{20}$ Relatório no formato de carta ao Inspetor Regional de Mato Grosso Adriano Metelo sobre o andamento dos trabalhos no posto Fraternidade Indigena. Microfilme 200. Fotograma 637. Muscu do Índio/FUNAI - RJ.

${ }^{21}$ Relatório no formato de carta ao Inspetor Regional de Mato Grosso, Adriano Metelo, sobre o andamento dos trabalhos no posto Fraternidade Indigena. Microfilme 200. Fotograma 637. Muscu do İndio/FUNAI - RJ.
} 
capacidade dos agentes em fornecer os brindes que eles próprios inventaram. E esta poderia ser uma tática de esgotamento da capacidade de ação. Essa impossibilidade de pensar o outro fora dos esquemas classificatórios cria situações aparentemente "absurdas" que só podem ser explicadas a partir de categorias definitivas, ou supostamente auto-explicativas, tais como: são brutos por excelência, são viciados, e várias outras adjetivações desse tipo.

Este foi o caso do ataque com arcos e flechas ocorrido no posto, interpretado como sendo uma reação à falta de brindes. Na primeira oportunidade que tiveram, os Umutina surpreenderam dois agentes que trabalhavam na roça. Um deles era o trabalhador Francisco Barbado - índio do grupo Umutina, considerado "civilizado", e que ajudava no processo de aproximação dos outros índios junto ao SPI; este era no momento o único alvo certeiro.

Comunico-vos para os fins devidos que devido à falta de brindes aos índios fomos no dia 14 de corrente mês surpreendidos com o lamentável incidente de terem sido flechados dois dos meus companheiros quando trabalhavam na roça. Foram eles os empregados Francisco Barbado e Benedito Venâncio. $O$ primeiro foi ferido 22 .

O recado parece ter sido dado, pois o contato se constituía de fato mediante a "doação" de brindes, scm estes não havia aproximação possível, nem mesmo com Francisco Barbado, que conhecia os seus costumes e hábitos e fornecia informações para os agentes. Pelo visto, Francisco cometeu o mesmo erro de Severiano Albuquerque ao subestimar a disposição reativa dos Umutina.

De acordo com a documentação, até o ano de 1915 os agentes ainda não tinham conseguido entrar nos aldeamentos dos Umutina e nem mesmo conheciam a população feminina. Até então, nenhuma mulher tinha ido até o posto de atração junto com os outros índios, que normalmente apareciam em grupo de até cinqüenta pessoas, entre homens e crianças do sexo masculino.

22 Ofício de $\mathrm{n}^{\circ}$ 06, enviado ao Senhor Raymundo Hosterno, em Cuiabá, no ano de 1915. Microfilme 200. Fotograma 629. Museu do Índio/IFUNAI-RJ.

Temáticas, Campinas, 16(31/32):219-241, jan./jun. 2008 
Mesmo desconfiados e aparecendo sempre armados no posto de atração, os Umutina não deixaram de fazer visitas com a intenção de conseguir brindes. De acordo com os relatórios, a desconfiança dos índios era $\mathrm{em}$ conseqüência das imprudências cometidas pelos poaciros ${ }^{23} \mathrm{e}$ seringueiros que protagonizaram encontros sangrentos com os Umutina em locais exteriores ao campo de ação dos agentes do SPI (Schultz, 1962, p. 84).

No ano de 1919, após cerca de cinco anos de contato e instalação do posto, o encarregado Severiano Godofredo Albuquerque, na tentativa de descrever o quanto estava sendo difícil o processo de atração, comparou os Umutina com índios de outras etnias, como os Bororo e os Nambikuara, considerando os Barbados muito mais "ferozes":

Resolvendo povoação Barra invasão pt índios Barbados representam quinhentos Bororos ou mil Nambikuaras estimando sua audácia estupidez $\mathrm{e}$ brutalidade pt pondo $\mathrm{cm}$ sacrificios vidas trabalhadores pt essa inspetoria resolverá como melhor convier $\mathrm{pt}^{24}$.

A façanha da "pacificação" foi conseguida pelo agente Helmano dos Santos Mascarenhas que foi designado pelo SPI, em 1919, para ajudar Severiano na difícil empreitada. Para o Serviço de Proteção aos Índios, foi Mascarenhas que conseguiu o "grande feito" de "pacificar definitivamente" os Umutina. Depois de várias tentativas, dentro do período de um mês, o agente conseguiu adentrar a aldeia Umutina. O relato etnográfico de Mascarenhas demonstra a

\footnotetext{
${ }^{23} \mathrm{~A}$ denominação poaciros vem da extração da poaia, também conhecida como ipecacuanha, ou ainda ipecunha. $O$ arbusto possui nas suas raizes propriedades medicinais, tornando-se matéria-prima na indústria farmacêutica. Éncontrada no interior de mata cerrada, a poaia ganhou o mercado estrangeiro, de forma sistemática, ainda no século XIX, c o mercado interno brasileiro começou a consumir o produto a partir de 1940. O extrativismo poaciro e o boom da borracha fizeram com que levas colonizadoras oficiais e particulares delineassem rotas, que sob a lógica do dinheiro avançavam sobre as frontciras, ignorando a legitimidade da ocupação dessas terras pelos grupos indigenas que estavam fixados nestes territórios desde tempos imemoriais.

24 Telegrama de 11 de março de 1919, endereçado para a Inspetoria cm Cuiabá. Mierofilme 200. Muscu do Índio/[UUNAI-R].
} 
necessidade de observar todos os detalhes que poderiam mais tarde servir como importante informação para o processo de pacificação:

Chegamos à casa do cacique no dia 28 de maio, às 13 horas, sendo a mesma coberta com folhas de palmeiras e o chão forrado com esteiras de cacté. Vi num canto da casa, um tecedor com uma tanga começada. A casa media vinte e cinco palmos de comprimento, por 20 palmos de largura, pouco mais ou menos, construindo dentro da mata, só derrubado o lugar onde a mesma foi feita, distando mais dos outros, uns 50 metros mais ou menos e ligado por picadas. De passagem contei 20 casas $^{25}$.

Dando continuidade ao relato, Mascarenhas afirma que em território Umutina ele foi obrigado a aceitar o protocolo dos índios. Na aldeia, eles ditavam as regras e se comportavam exatamente como os agentes na recepção aos índios no posto. Assim fazendo, ficavam invertidas as posições usuais entre índios e agentes: "Ofereceram-me mel que aceitei. Enquanto o cacique historiava a viagem, eles arrumaram-me os cabelos, tingiram-me o corpo com tinta de urucu, colocando a testeira do chefe ${ }^{26}$ na minha cabeça" (Schultz, 1962 , p. 85).

A postura defensiva dos Umutina foi quebrada, de fato, logo depois de ter estourado uma epidemia de sarampo na mata que matou $1 / 3$ da população, vitimando 300 índios. O relatório anual de 1920 relata a fragilidade dos Umutina frente às doenças trazidas pelo contato com os "civilizados", ou melhor, com os agentes quando da visita à aldeia.

As doenças epidêmicas como coqueluche, a gripe e o sarampo, foram os golpes fatais sobre qualquer ação reativa que permanecesse entre os índios.

\footnotetext{
${ }^{25}$ Relatório anual de 1920, folhas 12,13. Biblioteca do CIMI - Comissão Indigena Missionária/Cuiabá. ${ }^{26}$ Harald Schultz, que também tra\% este documento $\mathrm{cm}$ sua separata, explica que a "testeira do chefe" deve ter sido o diadema de penas de peito de arara vermclha, usado por todos os homens, pois entre os Umutina não existia o statıs de chefe de aldeia, a não ser o de chefe de excursões guerreiras, dos cerimoniais e da pesca de timbó. Mascarenhas, ao enfatizar a testeira como se fosse do chefe, parece ter a intenção de dar ao fato maior visibilidade para impressionar os dirigentes do SPI, dando a entender que os indios o reconheciam como chefe. In: Schultz (1962)
}

Temáticas, Campinas, 16(31/32):219-241, jan./jun. 2008 
A única alternativa foi abrir a guarda na possibilidade de encontrarem a cura junto aos mesmos que haviam levado as doenças. Contudo, mesmo essa saída, que apresentava-se na ocasião como a única possível, foi em vão, posto que os agentes não tinham na farmácia do posto os recursos e medicamentos necessários:

Trabalho insano c improficuo, não nos dando prazer, já pela rapidez que a moléstia alastrava e o furor dos índios contra $\mathrm{mim}$, dizendo que o único culpado deles morrerem, somos nós, que do nosso meio é que levaram a moléstia, como também somos forçados a reconhecer que não dispomos de meios para debelar tão terrível mal. Possuía no posto somente uma quantidade insuficiente de remédios contra cesão que não nos serviu, restando-me o último recurso, de isolar os infestados pelo mal. Os sãos levci-os para as proximidades dos seringais do alto Paraguay, deixando os doentes pouco acima da Cachocirinha ${ }^{27}$.

No mesmo documento, Severiano Godofredo Albuquerque refere-se ao total de 300 mortos entre os convalescentes e ainda narra um desabafo do índio Boepá, que sabia perfeitamente o preço de terem aceitado os brindes do SPI:

Restam unicamente duzentos convalescentes, com aspectos de cadáveres e não dos valentes Barbados que pacifiquei. Com que pesar ouvi Boepá falar, momentos depois de sua mulher Paurpé expirar nos braços do Bororo Kutipi Bacureus: 'De que nos serve tanta farinha c roupa se morremos todos de moléstias que vocês nos passaram. Agora que todos nós morremos, você diz ser nosso amigo, porque não nos cura?' E éramos impotentes para debelar o mal'

\footnotetext{
${ }^{27}$ Relatório anual de 1920 , referente ao ano de 1919 . Microfilme 200. Folhas avulsas, sem a
possibilidade de visualização dos números do fotograma. Museu do Índio/FUNAI - RJ.

${ }^{28}$ Relatório anual de 1920, referente ao ano de 1919. Microfilme 200. Folhas avulsas, sem a possibilidade de visualização dos números do fotograma. Museu do Índio/FUNAI - RJ.
}

Temáticas, Campinas, 16(31/32):219-241, jan./jun. 2008 
Em meio às ações de pacificação, ao longo de todo o processo, as doenças acabaram sendo as grandes aliadas dos agentes pacificadores, pois mesmo com toda a indignação que as moléstias provocavam entre os Umutina, todos ficavam, em geral, extremamente fragilizados após as epidemias, buscando qualquer ajuda e submetendo-se àqueles que poderiam tirá-los de tal situação.

Nesse episódio de extermínio e em outros que envolviam outras etnias pela introdução de epidemias (coqueluche, sarampo, gripe e a broncopneumonia), ficam evidentes os efeitos de poder que o saber "científico" proporcionava, neste caso conferido aos enfermeiros e médicos, que passavam a ter em suas mãos o poder de vida e morte de toda uma sociedade fragilizada e ameaçada de extinção.

Essa fragilidade foi utilizada pelos agentes do SPI para manter os índios mais próximos e efetivar uma relação mais duradoura. Essa estratégia, aliada ao sistema de brindes, serviu de maneira eficaz para o agente Mascarenhas, que aproveitou a situação para fazer os índios "entenderem" que os presentes eram oferecidos por "amizade" e não porque os agentes tinham algum receio deles. Ao menos, na perspectiva de Mascarenhas, os Umutina teriam finalmente compreendido o significado dos brindes, passando daí em diante a trocar o brinde por trabalho: hoje o aborígine Barbado trabalha com prazer para poder fazer jus ao brinde ${ }^{29}$.

As epidemias, mesmo em meio ao horror que estas provocaram entre os índios, acabou consolidando o posto, seja no atendimento imediato, seja no acolhimento das crianças que ficaram órfas durante a tragédia. Foram elas as responsáveis pela composição formal do corpo social do posto como os seus "verdadeiros" moradores, os índios, conforme os objetivos do projeto civilizatório. Logo após a pacificação irrompeu uma epidemia entre os Umutina da selva. Muitos morreram! Os órfãos foram recolhidos pelo pessoal do posto indígena e por eles educados (Schultz, 1953, p. 11).

O encarregado Severiano Albuquerque ficou no posto Fraternidade Indígena até setembro de 1921, assumindo em seu lugar - a partir de outubro

\footnotetext{
29 Relatório anual de 1920, referente ao ano de 1919. Microfilme 200. Folhas avulsas, sem a possibilidade de visualização dos números do fotograma. Muscu do İndio/FUNAI- RJ.
}

Temáticas, Campinas, 16(31/32):219-241, jan./jun. 2008 
do mesmo ano -, o agente do SPI Otaviano Calmon, cujo relatório do ano de 1923 traz um dado importante a respeito do consumo de bebidas alcoólicas e cigarros. Estes dois itens são conhecidos pela historiografia como importantes elementos no processo de atração, desde o Brasil Império. A antropóloga Marta Rosa Amoroso (2002) coloca-os entre os principais produtos utilizados na cooptação dos índios, juntamente com o sal e o açúcar.

$\mathrm{Na}$ documentação analisada apenas esse relatório menciona bebidas $\mathrm{e}$ cigarros, todavia, pela forma como são citados, nos faz supor que se trata aqui de uma ação fracassada junto aos Umutina, mas que poderia ter sido experimentada. Reforça nossa leitura a convicção demonstrada no relatório, conforme trecho que se segue: figura o fato muito notado de não terem eles nenhum vício, tendo mesmo horror aos vícios dos civilizados, tais como: fumo e bebida, seja de que qualidade for $^{30}$.

No mesmo relatório, o encarregado Otaviano Calmon trata da reação das crianças aos brindes, pois os agentes, mais uma vez, subestimaram a capacidade e a disposição dos Umutina de dizerem não, inclusive entre os pequenos.

Havia um entendimento dos agentes de que com as crianças a aproximação seria mais fácil, afinal elas poderiam se encantar com os objetos que nunca viram ou ainda querer experimentar sabores desconhecidos. Entre os adultos, eles sabiam que havia a necessidade da negociação para que a troca fosse estabelecida, mas não esperavam uma mesma reação da parte das crianças: a sua natural altivez se revela bem claramente no fato de não pedirem cousa alguma a ninguém por mais que a desejam possuir; isso se dá mesmo com as crianças ${ }^{31}$.

O que pretendemos é mostrar que as instruções do SPI eram faliveis, ou que não se realizavam exatamente como haviam sido pensadas e definidas; dependendo da especificidade do grupo de índios em questão algumas ações poderiam ser reformuladas diante dos vários contextos - como, por exemplo,

\footnotetext{
${ }^{30}$ Relatório ao Inspetor interino do SPI cm Mato Grosso, Antônio Martins Vianna Estigarribia, $\mathrm{cm}$ dezembro de 1923. Microfilme 200. Fotograma 1147. Museu do Índio/FUNAI- RJ.

${ }^{31}$ Relatório à Inspetoria Interina cm Mato Grosso do encarregado do posto Otaviano Calmon, cm dezembro de 1923. Microfilme 200. Fotograma 1147. Museu do Índio/FUNAI-RJ.
}

Temáticas, Campinas, 16(31/32):219-241, jan./jun. 2008 
diante do processo de negociação algumas delas não chegavam a ser colocadas em prática, enquanto outras, improvisadas pelo posto, acabavam sendo incorporadas, uma vez que também visavam à pacificação e à incorporação dos índios ao território nacional. É exatamente para dar conta dessas ações que foram negociadas que procuro privilegiar uma abordagem fundamentada na micro-história, que:

\begin{abstract}
"se apóia no exame das rupturas, das incocrências e das incompreensões que surgem nos documentos, conferindo uma importância considerável nas trocas verbais: 'Devemos procurar nos apoiar nos raros casos em que a documentação tem um caráter dialógico no sentido que não é o de um diálogo formal"' (Ginzburg, 1991)"32.
\end{abstract}

Abrindo uma cortina para a apreensão das dobras e dos revezes da história, desde as micro-reações - silenciosas, sorrateiras c sombrias -, até as explícitas, anunciadas c articuladas, ć possível compreender uma teia de relações c embates que foram velados por uma história positivista, através de um discurso homogeneizante do SPI, que procurava forjar uma "verdade" a tudo que era atribuído aos índios, sobretudo quando os grupos indigenas mudavam-se para o interior dos territórios recortados pelo Estado, denominados de posto indígena.

Entretanto, afirmar que os índios em questão foram pacificados de maneira consolidada, e portanto inquestionável, não nos permite entender com profundidade o que essas relações entre agentes e grupos indígenas produziram e continuam produzindo em termos de alteridade e conformação; principalmente quando se trata de reconhecer que essas unidades que hoje são territórios indígenas, ao longo de todo esse processo histórico, vêm re-significando e afirmando que são grupos com identidades e culturas próprias.

\footnotetext{
${ }^{32}$ Apud Alban Bensa: Da Micro-História a uma Antropologia Crítica. In: Jogos de Escalas - A Experiência da Microanálise/Jacques Revel; Organizador. Editora FGV. 1998. Pág. 48.
}

Temáticas, Campinas, 16(31/32):219-241, jan./jun. 2008 
ABSTRACT: The SPI - Service of Protection to the Indians - was created in order to take action to the Indians of Brazil to mediate the existing conflicts between indigenous groups the and non-indians; and also to facilitate the colonization among the indians, from the beginning of XX century, in 1910. Into this historical-social context, the aim is to outline a historical ethnography through the microanalysis of the SPI's documentation, setting light in the contact relations produced by means of gifts and the reaction of the Indians, in this case, the Umutina people from the state of Mato Grosso - West Frontier, in the period between 1910 and 1923.

KEYWORDS: indigenist politics, SPI, attraction of indians

\section{BIBLIOGRAFIA}

AMOROSO, Marta Rosa. "Conquista do Paladar. Os Índios, o Império e as Promessas da Vida Eterna”. Seminário FUNARTE, Brasil 500 Anos. Experiência e Destino. Nação e Região. Brasília: FUNARTE, 2002.

BENSA, Alban. Da Micro-História a uma Antropologia Crítica. In REVEL, Jacques (org.). Jogos de Escalas - A Experiência da Microanálise. São Paulo: Editora FGV, 1998.

CABRAL, Octaviano. "Histórias de uma região - Mato Grosso, fronteira Brasil-Bolivia e Rondônia”. Rio de Janciro.1963.

CERTEAU, Michel de. A Invenção do Cotidiano. 1. Artes de fazer. $6^{\mathrm{a}}$ edição. Petrópolis: Editora Vozes, 1994.

LIMA, Antonio Carlos de Souza. Um grande cerco de paz: poder tutelar, indianidade e formação do Estado no Brasil. Petrópolis, RJ: Vozes, 1995.

REVEL, Jacques. “A História ao Rés-do-chão”. In LEVI, Giovanni. A Herança Imaterial: trajetória de um exorcista no Piemonte do século XVII. Rio de Janeiro: Civilização Brasileira, 2000.

REVEL, Jacques (org.). Jogos de Escala - A experiência da Microanálise. São Paulo: FGV, 1998.

SCHULTZ, Harald. Informações etnográficas sobre os Umutinas. São Paulo: Revista do Museu Paulista, Nova Série, Volume XIII, 1962. 